\title{
A Smart Mobile Learning Conceptual Framework for Professional Development of UAE In-Service Teachers
}

\author{
Athra Sultan Alawani \\ Hamdan Bin Mohammed Smart University \\ Proffesor Abtar Darshan Singh \\ Hamdan Bin Mohammed Smart University
}

\begin{abstract}
Increasingly, mobile learning has been considered as a part of professional development due to its unique attributes: ubiquitous, flexible, highly personalized and easily accessible. It represents a paradigm shift for continuous professional development especially amongst teachers who have a tight working schedule. This paper will provide a conceptual framework for the design of a mobile learning course for UAE teachers' professional development. It aims to assist teachers to continuously engage in professional development activities and mitigating challenges such as time constraints, suitability of training content, impactful strategies and personalization of learning. A smart conceptual framework based on the three important principles of learning design was developed and pilot tested. The main elements of the conceptual framework and the results of the pilot test are presented in this paper.
\end{abstract}

Paper type: Research paper

Keywords: Teacher Education, Professaional Development, Mobile Learning, UAE, Mobile Technologies, Educational Technology 


\section{A Smart Mobile Learning Conceptual Framework for Professional Development of UAE}

In-Service Teachers

\section{Introduction}

The UAE upholds the value of education as the main tool for human development. There is a strong awareness of the need to reach sustainable human development in a globalized context to keep pace with the rapidly changing world. One of the crucial elements in the education system reform is the improvement of teaching quality through effective professional development as emphasized by Alhassani (2012) that there is a strong connection between students' performance and teaching quality. Certainly, teachers must be equipped with adequate knowledge, skills and awareness in order to perform better. Accordingly, there is a need to rethink professional development for educators. Nowadays, technological and educational innovation can empower both educator and learner to enhance learning experience. Advances in technology not only allow borderless education that is accessible, scalable and also flexible.

UNESCO (2012) had shed light on the necessity to use mobile devices to develop education for all purposes especially the following: those facing challenges in a particular educational context, enrich formal schooling, and those related to creating a more equitable, accessible, and flexible learning for learners anywhere and at any time (Franklin, 2011). This paper is an effort towards the development of a conceptual framework for an effective training environment using mobile tools which is oriented to serve teacher professional development in the UAE and the Arab region.

\section{Purpose and Importance of the Study}

The key enablers for the current diffusion of mobile learning include the emergence of online cloud computing management systems, increased use of mobile instructional resources and social networking into learning process. This undoubtedly creates a new and powerful way of teaching and learning. There is inherent sense of personalizing the device to meet individual needs, behaviors and life and work patterns (Mitchell \& Reushle, 2013). Mobile phone users use their devices for various purposes and find the right blend for their purpose, environment and outcome. Mobile-learners thus have a sense of ownership and control of when and how they like to learn, connect, communicate and collaborate with content (Mitchell \& Reushle, 2013).

Despite success in some aspects in the field of professional development in the UAE, numerous critical issues and concerns were highlighted by teachers in a study conducted by Buchner, Chedda \& Kindreich (2016) where the study showed that not all forms of professional development were considered useful. Teachers were not very satisfied with workshops and training mandated by education authorities. They claim that several programs were irrelevant, repetitive, and sometimes conducted by unqualified instructors. On the other hand, the teachers expressed a desire for more personalized professional training depending on their needs and more innovative methods than what is currently offered. Thus, there is an urgent need to create innovative smart training methods for teachers' professional development. Mobile learning can fulfil the need; however, most of the existing research is focused primarily on the benefits of mobile learning for

International Journal of Management and Applied Research, 2017, Vol. 4, No. 3 


\section{A Smart Mobile Learning Conceptual Framework for Professional Development of UAE In-Service Teachers}

students. There is a dearth of research for teacher professional development. As such there is need to develop research-informed guidelines and theoretical framework to suggest methods on how to integrate mobile learning into teachers' professional development.

Mobile learning is considered as an alternative and complementary way to support teachers' professional development in order to be more personalized and convenient to teachers and enable them to work, learn and reach their full potential within the workplace. Thus, the attempt of this study is to first create a framework that will be used to design mobile learning (or training) appropriate to the needs of teachers in the UAE. The framework is conceptualized using a learning design approach which according to Singh (2016) combines instructional design, personal and informed practices and other sciences The outcomes of this research will be useful for stakeholders within the educational fraternity such as schools, higher educational institutions, educational technologists, developers and designers of mobile learning to address teacher efficiency and effectiveness when attending PD programs.

\section{Objective and Research Questions}

The main objective of this study is to devise a conceptual framework for continuous professional development of teachers in the UAE using mobile devices especially the smartphone. Using a conceptual framework, a few lessons related to integrating technology in the classroom were created and tested. The following research questions guided this study:

1. What were the main attributes of the smart mobile learning framework for UAE in-service teachers?

2. What were teacher responses to a pilot test of the content created using this framework?

\section{Literature Review}

\subsection{Teacher professional development in the UAE}

In the United Arab Emirates (UAE), the educational authorities have launched several ambitious programs to improve the quality of education based on the nation's vision and strategic goals (Tabari, 2014). The Ministry of Education (MOE) has been focused on improving the standards of education in the country. The main aim is to ensure pupils are proficient in Arabic and English, knowledgeable in key content areas especially STEM and armed with $21^{\text {st }}$ century skills. They are also expected to be committed to their heritage and prepared for entry into higher education (Tabari, 2014). Alhassani (2012) emphasized that there is strong connection between students' performance and teaching quality. The UAE education system is yet to reach the desired high quality standards on par with the more developed educational systems in other countries. One of the key enablers of effective education systems is the continuous professional development of teachers. This is confirmed by studies that consistently put the emphasis on teaching

International Journal of Management and Applied Research, 2017, Vol. 4, No. 3 


\section{A Smart Mobile Learning Conceptual Framework for Professional Development of UAE In-Service Teachers}

attributes as one of the most important indicators of student learning (Broad \& Evans, 2006; Alhassani, 2012).

In addition to the fact that teachers must be equipped with adequate knowledge, skills and awareness in order to perform better; they also need to apply and incorporate different kinds of knowledge and skills to be used in various teaching and learning permutations fluently and flexibly (cited in Board \& Evans, 2006). Therefore, the strategic plan in UAE, Education 2020, highlights the importance of teacher quality (Buchner, Chedda \& Kindreich, 2016). The teacher today is one of the 21st century workers; so they need to be fast, flexible, self-directing and creative. There is still a gap between current and desired teacher professional development despite the implementation of a variety of professional development practices.

The MOE provides regular and centralized in-service professional development workshops three times per academic year which are held in the first week for each semester (there are three semesters per academic year) to support teachers and develop their practices. The training aims at ensuring teachers' mastery of the curricula, teaching strategies, ICT and promotion of skill-based learning. It is worth noting that the training is mostly in the form of short courses. Moreover, several schools have their own professional development initiatives. Teachers in the UAE have to achieve an average of 30 hours of professional development courses each academic year (Buchner, Chedda, \& Kindreich, 2016, Alhassani, 2012) as a requirement for their final evaluation report.

Teacher quality and continuous professional development have been key concerns in most nations. The UAE too face many challenges in order to ensure teacher quality and support teachers' professional development. This has led to a larger policy debate over what should be the priority: recruitment or professional development and retention. For recruitment, there is an emphasis on the educational requirements for entry into the profession in order to attract high-caliber applicants. On the other hand, the existing staff should be backed by on-going professional development programs once they are working in schools (Buchner, Chedda \& Kindreich, 2016). Furthermore, the teaching staffs in UAE schools come from various international backgrounds with high variances in their culture, behaviors, attitudes and norms. They may need different training programs.

Despite successes in some aspects in the field of professional development in the UAE, many other critical issues and concerns were highlighted by teachers in a study conducted by Buchner, Chedda \& Kindreich (2016) about mandatory professional development provided by educational authorities in UAE. Their study revealed the following findings:

- Making professional development mandatory for teachers to attend led to unintended consequences of turning professional development into inconveniences which may weaken its usefulness for some teachers.

- The content of professional development covered various topics such as subject matter, evaluation practices, and ICT integration in teaching and learning practices. However, there is need to focus on topics like teaching students with special needs,

International Journal of Management and Applied Research, 2017, Vol. 4, No. 3 


\section{A Smart Mobile Learning Conceptual Framework for Professional Development of UAE In-Service Teachers}

new technology in workplace, teaching in multicultural setting, and some content related to classroom management skills and parental and community involvement.

- Teachers preferred professional development conducted by the school as it responded more directly to the teachers' needs.

- Teachers prefer the existence of a teacher network in line with in-service and schoolbased training, where they can promote dialog, discussion, share experiences, knowledge and pedagogical tips.

- Teachers mention some barriers to participation in professional development, like lack of time because they are too busy due to overload work in schools and their families' responsibility, and administrators' obstacles when they are not actually supportive of professional development.

- Sometimes, teachers view professional development as a waste of time when it failed to meet their actual needs.

Taking the study of Buchner, Chedda \& Kindreich (2016) into consideration, mobile learning may serve as an alternative and complementary method for teacher professional development which may mitigate the barriers to professional developments for teachers in UAE.

\subsection{Mobile learning and teacher professional development}

Learning is acquiring new knowledge, skills, behaviors, values and adjusting existing ones and synthesizing various types of information (Franklin, 2011). Looking at it from a wider angle, mobile learning represents a paradigm shift in the nature of building knowledge in society, and thus the nature of learning in both formal and informal forms. Mobile learning is facilitated due to the proliferation of portable computing and mobile devices and more powerful and affordable internet connections. Franklin (2011: 261) defines mobile learning as "learning that happens anywhere, anytime." This definition indicates the flexibility, empowerment, and the ability of learners to learners to engage with other professionals, regardless of their geographical, cultural, or socio-political differences.

UNESCO (2012) provided an illustrative overview of emerging mobile learning initiatives that proposed to improve or expand access to teachers' professional development and support teachers' knowledge and skills in MENA (Middle East and North Africa). The report revealed that there is a lack of research-based evidence that mobile technology can enhance and support teachers' professional development. The report provided by UNESCO discussed the potential of mobile devices to support teacher development in: 1) overcoming teachers' technophobia; 2) supporting teacher training; 3 ) supporting teachers' teaching practices; 4) improving educational management and administration; 5) allowing for peer support for teachers; 6) extending teacher training to remote areas; 7) enhancing professional development; and 8) strengthening teachers' competencies in relation to ICT. The finding of UNESCO corresponds with academic research in relation to professional developments for teachers in online learning format.

International Journal of Management and Applied Research, 2017, Vol. 4, No. 3 


\section{A Smart Mobile Learning Conceptual Framework for Professional Development of UAE In-Service Teachers}

According to Park (2011), a lack of a solid theoretical framework for mobile learning can raise serious issues in creating effective learning design. Several attempts to conceptualize mobile learning have been made since the emergence of mobile devices and wireless technologies. In the context of teacher education, the literature shows that there is a lack of new approaches, models and frameworks designed specifically to develop mobile learning content to support teachers' learning and enhance their performance in teaching practices. Hence, there is a need to establish pedagogical and theoretical frameworks to design mobile learning experiences for teachers' continuous professional development.

The design of a mobile learning environment should start with taking into account 1) the real needs of educators and learners, 2) the social aspects of mobile technologies, 3) the 'as-lived-experience' of mobile learners, and 4) the factor of mobile technologies in learning which will be dependent on its adoption by both educators and learner (Standton \& Ophoff, 2013). Besides, in order to effectively integrate mobile learning in teachers' professional development, the designers and instructors of mobile learning courses need to go beyond the potentials of the tool to explore pedagogical benefits of mobile learning appropriate for various content areas and based on theoretically sound approaches. Furthermore, there is need to investigate how different types of mobile learning experiments have an impact on teachers' performance and in their teaching practices. In addition, it is important to explore the different types of designs, planning, engagements, feedback, reflections and assessments using mobile technologies. Eventually, the ability to promote teachers' learning through mobile technologies requires the teachers to be motivated, self-directed and self-regulated in their approach to professional practice (Marten, McGill \& Sudweeks, 2013 cited in Mitchell \& Reushle, 2013). Both motivation and engagement play an essential role in the teachers' attitude, energy and strong desire to work.

\subsection{Mobile Learning Design}

In order to conceptualize a framework for mobile learning, this paper used the learning design constructs proposed by Singh (2016) which are a combination of: instructional design, informed practices, and other sciences.

\subsubsection{Instructional Design}

Instructional design is a very important aspect of learning design and is highly related to theories of learning. Theories of learning have played a critical role in designing instructional resources to enhance learning experiences. Researchers agree on the need for an acceptable learning theory to support mobile learning. Muyinda (2007, cited in Dillard, 2012) argues that there is no existing learning theory encapsulating all the considerations related to mobile learning. Until specific theories of mobile learning are fully developed, many existing learning theories can be utilized for the conduct of learning appropriate for a mobile learning environment. For example, Ally (2009) presented the idea of taking advantage of cognitive learning instructional theories in developing mobile learning practices. Cognitive learning theory refers to the use of

International Journal of Management and Applied Research, 2017, Vol. 4, No. 3 


\section{A Smart Mobile Learning Conceptual Framework for Professional Development of UAE In-Service Teachers}

memory, thinking, motivation and reflection. Hence, the use of cognitive theory of learning can be highly incorporated into a mobile learning context alongside other theories such as behaviorist and constructive.

Muyinda (2007, cited in Dillard, 2012) argued that learning theories and corresponding strategies such as collaborative learning, situated learning, and informal and life-long learning could all or at least partially, meet the needs of designing mobile learning. Sharples, Taylor \& Vavoula (2005), argued that mobile learning broadly matches the social-constructivist approach to learning, which views learning as an active process of building knowledge and skills through collaboration with peers and instructors. They proposed five questions that can act as a checklist for developing a framework of mobile learning (Sharples, Taylor \& Vavoula, 2005):

1) Is it significantly different from the current theories of classroom, workplace or even lifelong learning?

2) Does it consider the mobility of the learners?

3) Does it include informal and formal learning?

4) Does it view learning as a constructive and a social process?

5) Is learning analyzed as personal and mediated by technology?

These questions not only provide a framework of mobile learning but also remark learning effectiveness. According to the Winkler et al. (2009), the effectiveness of mobile learning depends on two key factors: contextualisation and construction. Pedagogical sound learning is grounded on the whole learning processes, including spatial, temporal, device-related, as well as social or community context (Kovachev et al., 2011). Although mobile technologies offer opportunities to learn in a non-traditional way, instructional design play a critical role in success of mobile learning implementation.

In studying the key instructional design issues of mobile learning, Gedik et al. (2012) reported that the use of the ARCS (attention, relevance, confidence, and satisfaction) motivational model developed by Keller helped designers and instructors in developing course content and manage content effectively. John Keller's ARCS motivational model begins with getting the attention of learners, which follows by delivering course materials that are relevant to the past experiences of learners, or their academic needs or current jobs. The confidence which subsequently built up during the learning process helps to develop positive learning behaviour and attitude. And lastly, learners gain satisfaction during the learning process as well as in the end of process in the cases where learning needs are fulfilled (Huang \& Hew, 2016).

To help mobile-learners learn more effectively, Ally (2009) suggested designing course materials in manageable chunks. Griffin (2011 cited in Ally, Grimus \& Ebner, 2014) provided some tips to help design mobile learning content, that is to divide content into two-minute segments, adopt a conversational style of content delivery and develop mobile learning experiences that are elegant and emotional.

International Journal of Management and Applied Research, 2017, Vol. 4, No. 3 


\section{A Smart Mobile Learning Conceptual Framework for Professional Development of UAE In-Service Teachers}

Dillard (2012) argues that despite the potential of mobile devices in offering rich, multimedia learning experiences, there is a lack in models/frameworks for developing learning mobile applications. There is consensus by many researchers around the importance of integrated pedagogical and technical strengths of mobile technology into learning environment (Gedik et al., 2012). Therefore, in order to ensure appropriate usage and implementation of mobile learning, a thorough analysis is needed from a pedagogical and technological perspective (Ally \& Prieto-Blázquez, 2014).

The unique characteristics of mobile learning such as spontaneous, private, portable, bitesized, light-weight, context aware and interactive, personalised and connected (Gedik et al., 2012; Kovachev et al., 2011) supplement teaching and learning both formally and informally. However, the uniqueness of mobile learning can only be achieved through effective implementation of instructional design and content delivery, in a way that both learners and educators can optimise learning outcomes.

\subsubsection{Informed Practices}

Informed practices are all the accumulated practices that have proven that a particular system which was used was successful. For mobile learning, they will be related to the various experiments already conducted about the technological and screen designs. Thus, researchers and educators are looking for best practices to design and develop mobile learning content. Indeed, M-learning can only be delivered with an awareness of the special limitations and benefits of mobile devices, so one cannot simply apply known design requirements from E-learning into the M-learning context (Parsons, Ryu \& Cranshaw, 2007). The technical aspects of mobile technologies (e.g. bandwidth, screen size) poses special challenges to both educators and learners, especially when comes to content delivery, frequency, and duration (Gedik et al., 2012). These instructional design challenges mirrors to the barriers of micro learning. Kovachev et al. (2011: 1) define micro learning as "short-term learning activities on small learning units", which "consists of a fast, convenient and instant capture of the self-identified knowledge gaps" (ibid: 2). While social media such as Twitter and Instagram serve as a good source of disseminating information, micro-learners or mobile-learners need to make sense of short chunks of information and conceptualise them into useful knowledge.

Other informed practices centred on technology requirements as mentioned by Sharples, Corlett \& Westmancott (2002):

1) highly portable - designed to support learning whenever and wherever;

2) individual -designed to support individual learning, serve for individual learning styles and be adaptable to learners' abilities;

3) unobtrusive - designed to retrieve knowledge without the technology becoming a deterrent;

4) available - designed to enable communication with friends, experts and/or teachers;

5) adaptable - designed to be adaptable to situations and the individual's skills and knowledge development;

International Journal of Management and Applied Research, 2017, Vol. 4, No. 3 


\section{A Smart Mobile Learning Conceptual Framework for Professional Development of UAE}

In-Service Teachers

6) persistent - designed to be able to manage the learner's learning despite the changes in the technology itself;

7) useful - designed to be useful to learners for everyday chores;

8) User-friendly - designed in order to be easy for people to use and must not create technophobia among new users.

Similarly, Parsons et al. (2007) has also offered some more mobile learning practices:

1. Mobility of mobile environment: this can be conceptualized in different ways (mobility of the users, mobility of the services, and mobility of the device) and those aspects should be addressed both contextually and technically.

2. Different user profiles and their roles: where the users could be the core or secondary users. The core users who perform learning activities by using the mobile device features can be likened to learners. The secondary users who are involved indirectly with learning activities but have roles to play like content provider or instructor.

3. Awareness of constraints of the user interface: mobile devices suffer from small screens, awkward input methods and limited battery life. User interface is needed to be simple far from unnecessary complexity; fast loaded and operated as well as consumes reasonable power.

4. Employ many rich media objects: Mobile learning content is better delivered in small chunks rather than large units of information. It can be supported by appropriate use of multimedia types.

5. Communication support: mobile technologies afford the possibility of stable contact.

Together, the studies of Parsons et al. (2007) and Sharples et al. (2002) mirror to the work of Winkler et al. (2009), which highlighted that, contextualisation and construction are two key factors that lead to the effectiveness of mobile learning.

Mobile apps like Lynda, Coursera and LinkedIn courses that deliver mobile learning courses were evaluated and the following are some informed practices:

- They had a simple interface with attractive colours and images.

- The courses were easy to explore when searching for specific ones

- Courses are categorized according to topics. The learner can choose any subtopic from the course to access, which means they can choose what they need to learn

- There are clear titles, focus descriptions and clear objectives.

- There is overview of the course (time, date of lunching, instructors, audience, \# of viewers, skills). One can click on down arrow to read them, if needed due to small screen of mobile devices.

- All explanations of the course content from introduction to content are mainly in videos. The learners are passive receivers of the information.

- All the videos are of high quality in resolution and sound, but mostly rely on narration by the instructor with the use of graphic explanations.

International Journal of Management and Applied Research, 2017, Vol. 4, No. 3 


\section{A Smart Mobile Learning Conceptual Framework for Professional Development of UAE In-Service Teachers}

- The time of the videos is reasonable. It is not more than 5 minutes in LinkedIn. In Lynda, it depends on the topic of video. It can be more than 25 minutes like the video explaining graphic design applications.

- All shown videos can be downloaded for offline viewing.

- Few courses have quizzes or assessments at the end of each chapter or subtopic.

- They are mostly self-paced courses.

- There is no clear interaction strategy between learners and instructors.

Another application, Grovo which is a cloud-based training platform, provides a microlearning library with thousands of videos no more than 144 seconds long. It is meant to improve leadership and soft and digital skills. Their slogan is "Micro Learning, Macro Result". Grovo claims that its micro-learning approach is based on delivering small and focused steps by bite-sized videos, short assessments and real-world practice exercises. Their mission is to help employees continuously develop the skills and habits they need to succeed. The director of Grovo, Alex Khugin defines micro learning as "a process of learning using short, consumable and well-planned units". Grovo argues that micro learning can solve the problems of traditional training which surfaced from long, out-ofcontext and irrelevant on-the-job performance. Their approach in solving the problems of traditional training are: 1) Digestible by providing short lessons with a single learning outcome, 2) Point-of-need by its availability anytime and anywhere, and 3) Action-based by getting employee to immediately apply what they learn. Grovo offers a library of 4,700 videos with lengths of 60 to 90 seconds and organized by topic and depth levels.

Coursmos is another platform for delivering micro-learning courses. It is the first provider of the unique very short lesson style with maximum 3 minutes in length. It offers courses of various topics and disciplines especially in Business \& Marketing and Technology. The site is user-friendly and provide search feature to easily find the lessons that learners want. It has courses and each course is divided into lessons with a video for each one. There are no activities, quizzes or assessments, not even feedback or discussion.

Usability is an important aspect of mobile learning. Designers for mobile learning system should be concerned not only about usability goals but also user experience goals to assess whether the product is enjoyable, satisfying and motivating (Parsons et al., 2007).

An effective design of mobile learning materials should take into consideration the characteristics of mobile technologies as well as their potential, for example, careful design of the user interface to be simple and intuitive, easy for the user to illustrate and animate course, tolerance of error and use the power of cloud computing. Moreover, to promote an exciting learning experience through mobile devices, instructional designers should deliver content in the simplest possible format and use multimedia in a convenient way by breaking instructional materials into manageable chunks, offering interactive activities, quizzes and assessments, providing instant feedback and promoting discussion among users and experts. In fact, creating an efficient instructional delivery

International Journal of Management and Applied Research, 2017, Vol. 4, No. 3 


\section{A Smart Mobile Learning Conceptual Framework for Professional Development of UAE In-Service Teachers}

promotes learning, smarter and faster, anytime and anywhere. It helps users to achieve more and improve their performance.

\subsubsection{Other Sciences}

In order to ensure the highest return of the professional development provided by the mobile learning system, some other principles in applied sciences are also equally important. These include motivation, challenge, personal development, higher-order thinking skills etc. For this study, the following sciences are discussed: teacher motivation, challenge-based learning, personalised learning, and rewards.

Motivation has been generally viewed as energy or drive that moves people to do something by nature. Sinclair (2008) defined teacher motivation as a catalogue of intrinsic and extrinsic factors that encourage teachers to engage in certain practices and behaviors. Han and Yin (2016) highlighted two dimensions of teacher motivation: the motivation to teach and the motivation to remain in the profession. Furthermore, they are motivated when the learning task recognizes and includes their understandings and perspectives and when they see that they can be effective in learning something of value (Broad and Evans, 2006). There is evidence that highly motivated teachers are more likely to engage in professional development and improve their teaching performance (Sinclair, 2008).

Positive reinforcements such as recognition and rewards are common practices to raise self-esteem and strengthen desired employee behaviours. Giving recognition and rewarding professional achievements are particularly important for teachers engage in asynchronous learning format. Online learning poses a unique challenge in student motivation in comparison with the traditional face-to-face learning. There are many different factors that affect motivation to learn, ranging from the technical aspects (e.g. asynchronous learning format, users' mobile device capabilities, software and hardware requirements) to the psychological factors like sense of isolation and lack of active interaction between peers could explain why some online students felt less motivated to study in an online setting (Gedik et al., 2012; Lin et al., 2017).

Broad and Evans (2006) pointed out that an effective professional development should be personalized and responsive to the unique needs and context of the learner. The growing popularity of mobile technologies enables a more personalised professional development as compared to mass education in traditional classroom setting.

Challenge-based learning on the other hand builds on the successes of problem-based learning models with participants engaged in work scenarios. Nichols et al. (2016) recognized that challenged-based learning provides an efficient and effective framework for learning while solving real-world challenges. The framework is collaborative and hands-on. It starts by asking all participants (teachers, student, families, school community, etc.) to identify big ideas, ask good questions, discover and solve challenges, gain in-depth subject area knowledge, develop 21st-century skills, and share their thoughts with the world. Challenge-based learning can be used to provide professional

International Journal of Management and Applied Research, 2017, Vol. 4, No. 3 


\section{A Smart Mobile Learning Conceptual Framework for Professional Development of UAE In-Service Teachers}

problem program as an approach to motivate and engage teachers for effective participation as well as powerful impact.

Mobile device has become a popular platform for training either as an independent delivery mechanism or as a part of blended training programs (Dillard, 2012). Motivating users play a critical role for continuous and effective participation in mobile learning courses. Adult learners like teachers would like to have the opportunity to improve their teaching performance. Moreover, it is important to give the teachers opportunities to advance themselves in order to fulfil their self-actualisation needs and career growth.

\section{The Conceptual Framework}

Based on the above literature review the following framework was conceptualized to deliver courses for the professional development of teachers in the UAE using mobile technologies (see Figure 1).

Figure 1: A Conceptual Framework for Smart Mobile Learning System for Professional Development of UAE In-Service Teachers

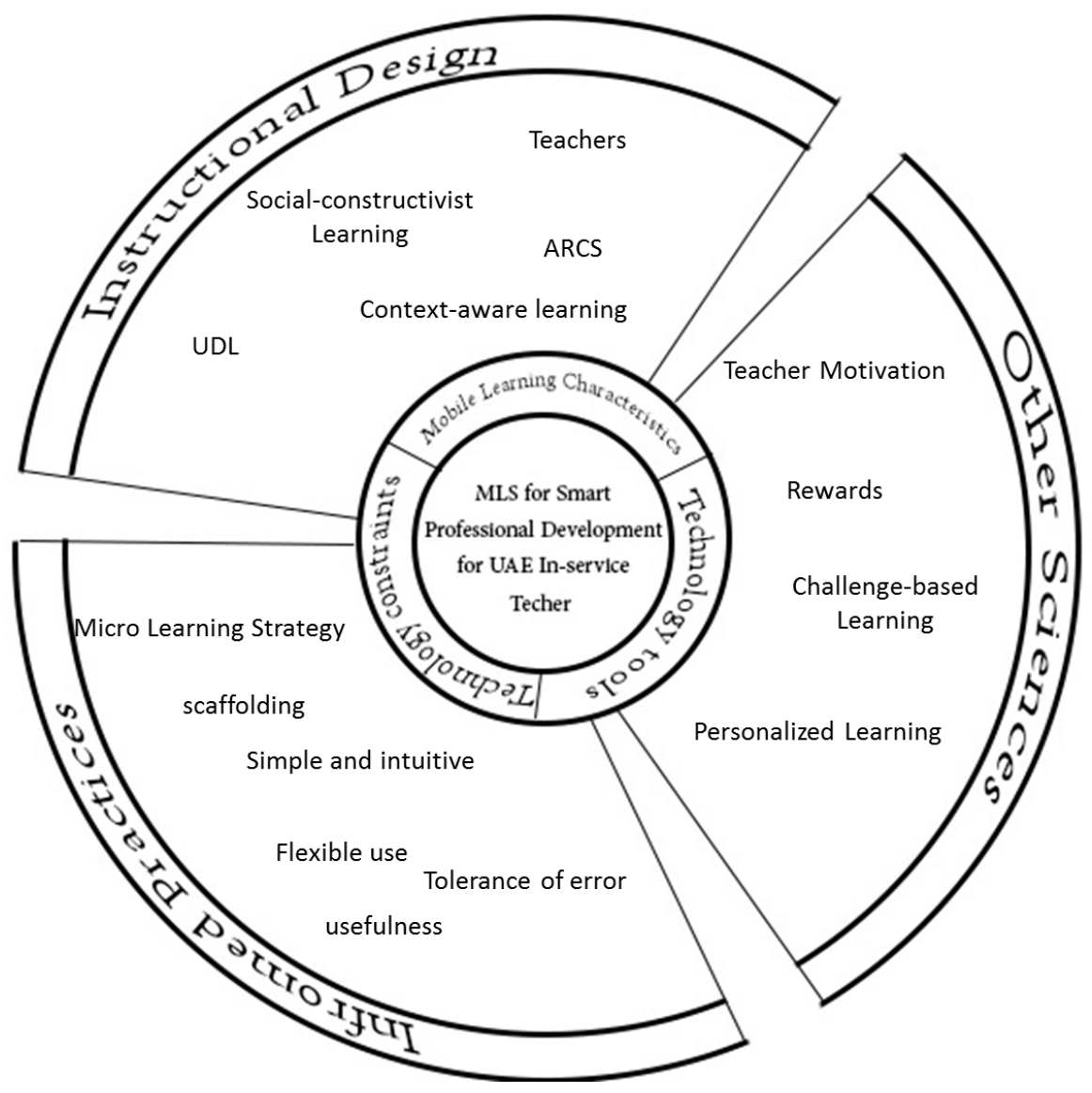

International Journal of Management and Applied Research, 2017, Vol. 4, No. 3 


\section{A Smart Mobile Learning Conceptual Framework for Professional Development of UAE In-Service Teachers}

Gedik et al. (2012) noted that cultural differences might affect the effectiveness of learning outcomes as well as the design, implementation, and evaluation of mobile learning.

UAE teachers are looking for sustained, on-going, in-depth and manifesting active engagement in professional practices (Buchner, Chedda and Kindreich, 2016). The proposed framework for providing professional development courses through mobile technology is due to rapid evolution with the great appreciation from teachers besides its ability to meet their learning needs at anytime and anywhere. The conceptual framework is contextualized to fit the needs of UAE teachers in modelling the mobile learning design elements (instructional design, informed practice and other science).

\section{Instructional Design}

A combination of key characteristics of instructional design models (such as learning guidance, practice and feedback from Gagne) ARCS motivational model and universal design for learning will be used. Some of the important elements from the combination of these models will be attract attention, making content relevant, building confidence, using different strategies to present content ( case study, story-telling, scenarios, problem based learning), tasks and feedback on task, and assessment of learning. Universal design for learning principles will be highly incorporated to ensure personalization of learning.

\section{Informed Practices}

From the informed practices, the conclusion are the design of simple and intuitive interface, utilize the rich-multimedia kinds, deliver content in the simplest possible format as modular and short lessons, provide contextually relevant and meaningful content, and has entertaining and engaging activities. Moreover, the mobile learning system should be tolerance of error, use the power of cloud computing and just -in-time delivery.

\section{Other Sciences}

In this study, other sciences refer to teacher motivation, rewards, personalisation, and challenged-based learning.

Unlike learning in a typical brick-and-mortar classroom, learning in a virtual setting requires learners to exercise more autonomous control over their learning attitude (Gedik et al., 2012), and strong motivation was a prerequisite for such self-regulated learning, which in turn affects the completion rate of online courses (Lin et al., 2017). Reward has been long recognised as a positive reinforcement to desired professional achievement and performance; and in UAE, there are many educational rewards for teachers that have encouraged high participation and competition among teachers.

The chances to personalise learning meet the urgency of learning need, either on demand or just in time. In this way, learners have full control over their learning process. On the other hand, challenge-based learning takes the learners back to real-life setting by solving problems in workplace scenario.

International Journal of Management and Applied Research, 2017, Vol. 4, No. 3 


\section{Pilot Study}

\subsection{Course Content Design}

Based on the proposed conceptual framework a course on "how to integrate technology into classroom practices" was developed for UAE teachers' professional development and pilot tested. Office Mix and ready-made videos were used to develop the mobile content whereby the videos were edited into short clips. Each micro lesson consisted of one video and one pop quiz or activity. The course also had a final micro project. The pop quizzes and activities were interactive and were simulated so that the participants could interact with them. There was instant feedback in the pop quiz Furthermore; a tutorial was created as an extra resource for each lesson in the course. The full lesson is available in the link below (See also the Appendix 1).

\subsection{Testing Procedure}

A simulated lesson using Office Mix features was created and uploaded to Mix Online for exploration and evaluation. The evaluation checklist was developed in both Arabic and English (see the appendix 2). Teachers who participated in the evaluation of the course were volunteers and conveniently selected. Seven teachers tested the course based on the developed checklist where both the URL of the course and the checklist file were sent to the teachers to evaluate the micro course. Feedback was also collected using interview method.

\section{Findings}

The following is a summary of teachers' responses:

1. Course content: $100 \%$ of teachers highly agree with the usefulness of content and its sequence. They stated that the objectives were clear and specific, which is starting from, installing the application, using it, and publishing the product. Furthermore, the video content was directly related to the lesson's objective and to the course topic. One teacher highlighted the need of a more clarified syllabus of the course which has an introduction of the course and provide more details about the course content vis-àvis the timeline to help the teacher to make a decision on whether to take the course.

2. Use of media: $100 \%$ of teachers like the use of videos as the basic delivery form; however, they suggested diversifying the forms of delivery.

3. Activities: Most of the teachers stated that the interactive activities were easy though they have instant responses. They expressed the need of activities that promote higher order thinking and challenge them.

4. Promote discussion: All teachers stressed the importance of a discussion board to promote sharing and collaboration between them. They suggested the discussion board to be in each course and not a general platform.

5. Practical assignment promotes innovation: All the teachers stated that innovation is based on the level of teachers' participation and final product besides their own

International Journal of Management and Applied Research, 2017, Vol. 4, No. 3 
motivational level. Thus the incorporation of creation of an innovative project is crucial.

6. Feedback system: There was instant feedback in the pop quiz. Some teachers expressed the need of more innovative way for feedback. Two of the teachers highlighted the need of discussion under each part of content and supervised from the instructor.

7. Interface: $71.4 \%$ of teachers were highly satisfied with the interface, which is simple and attractive. It has suitable screen structure and font/media size. Others stated the need of more professional and attractive design.

8. Usability: $57.1 \%$ of teacher expressed that the content was easy to browse and there were various accessible ways to specific content. Other teachers acknowledged the features of touch screen of smart phones in movement like tap on the screen, double tap, swipe of flick, tilt and move etc. should be utilize in navigation and interact with content.

9. Inspiring teacher motivation: $100 \%$ of teacher stressed their interest to complete the course because of its relevance and the motivational strategies to learn.

10. Reward strategy: there is positive message when they solve the quiz right. One teacher suggested 'pioneer' reward for effective participant and another stated the need for looking for more innovative rewarding strategies to encourage teachers' participation.

On the whole, the participants' responses to the evaluation of the course were positive. All the teachers $(100 \%)$ agreed that this is a new initiative in education, and they are excited to use this platform. $71.4 \%$ stated their satisfaction about learning using the mobile device which was easier than using the computer and was more fun. They also said that the screen designs were attractive, interesting and beneficial as their learning process was more impactful. One respondent hoped that more courses will be delivered in a similar way covering various topics.

\section{Conclusion}

This paper discussed how a model for the design of mobile content was conceptualized. A learning design framework was used to collate literature related to instructional design, other sciences and informed practices. These assisted in bringing all the important elements of learning design into a focal point of the conceptual framework. The major elements of the learning design are a combination of instructional design elements such as systematic design, using impactful strategies to attract, retain learning and be engaged in the learning. These strategies include and are not limited to using scenarios, case studies, problem-based learning and task-based learning which are presented using rich and engaging resources such as videos, gamification and simulations. Building participant confidence and satisfaction (drawing on ARCS motivational models) is highly emphasized by providing relevant Arab oriented content. The learning design is enhanced by incorporating appropriate informed practices suited to mobile technology such as micro content and easily navigable interfaces. Other sciences that are important were considered and this includes challenged-based learning- an element which is highly

International Journal of Management and Applied Research, 2017, Vol. 4, No. 3 


\section{A Smart Mobile Learning Conceptual Framework for Professional Development of UAE In-Service Teachers}

emphasized by UAE leaders. Other important elements include positive reinforcements and personalisation.

In the future, this framework will be studied further and tested with larger groups of the target audience. It can be considered as the starting point of pedagogical and technological design of mobile learning courses proper for Arab region as well as for a more global audience. Moreover, the framework will be a good guidance for instructional designers to create and design meaningful instruction of mobile learning.

\section{References}

1. Alhassani, J. (2012), Primary English Language Teachers' Perceptions on Professional Development Programs in Public Private Partnership Schools in Al Ain, United Arab Emirates. Master of Education Program. United Arab Emirates University.

2. Ally, M. (2009), Mobile learning, Edmonton: AU Press.

3. Ally, M. and Prieto-Blázquez, J. (2014), "What is the future of mobile learning in education? Mobile Lear-ning Applications in Higher Education", Revista De Universidad Y Sociedad Del Conoci-Miento (RUSC), Vol. 11, No. 1, pp. 142-151. https://doi.org/10.7238/rusc.v11i1.2033

4. Ally, M., Grimus, M., and Ebner, M. (2014), "Preparing teachers for a mobile world, to improve access to education", Prospects, Vol. 44, No. 1, pp. 43-59. https://doi.org/10.1007/s11125-014-9293-2

5. Broad, K. and Evans, M. (2006), A Review of Literature On Professional Development Content And Delivery Modes For Experienced Teachers. Canada: University of Toronto.

6. Buchner, E., Chedda, S. \& Kindreich, J. (2016). Teacher Professional Development in the UAE: What Do Teachers Actually Want?. Policy Paper No.16. RAK: Sheikh Saud Bin Daqr Al Qasimi Foundation for Policy Research.

7. Dillard, A. (2012). Mobile Instructional Design Principles for Adult learners (Master Thesis, USA: University of Oregon.

8. Franklin, T. (2011), "Mobile learning: at the tipping point", Turkish Online Journal of Educational Technology, Vol. 10, No. 4, pp. 261-275.

9. Gedik, N.; Hanci-Karademirci, A.; Kursun, E. and Cagiltay, K. (2012), "Key instructional design issues in a cellular phone-based mobile learning project", Computers \& Education, Vol. 58, No. 4, pp. 1149-1159. https://doi.org/10.1016/j.compedu.2011.12.002

10. Grovo (2017), Redefining learning for today's workforce. [Online] Available from http://www.grovo.com [Accessed on 2 June 2017].

International Journal of Management and Applied Research, 2017, Vol. 4, No. 3 
11. Han, J. and Yin, H. (2016), "Teacher motivation: Definition, research development and implications for teachers", Cogent Education, Vol. 3, No. 1, https://doi.org/10.1080/2331186X.2016.1217819

12. Huang, B. and Hew, K. (2016), "Measuring Learners' Motivation Level in Massive Open Online Courses", International Journal Of Information And Education Technology, Vol. 6, No. 10, pp. 759-764. https://doi.org/10.7763/ijiet.2016.v6.788.

13. Kovachev, D.; Cao, Y.; Klamma, R. and Jarke, M. (2011), "Learn-as-you-go: new ways of cloud-based micro-learning for the mobile web", presented in: 10th International Conference on Web-Based Learning, Hong Kong, December 8-10, 2011. https://doi.org/10.1007/978-3-642-25813-8

14. Lin, C.; Zhang, Y. and Zheng, B. (2017), "The roles of learning strategies and motivation in online language learning: A structural equation modeling analysis", Computers \& Education, Vol. 113, pp. 75-85. https://doi.org/10.1016/j.compedu.2017.05.014.

15. Mitchell, M. \& Reushle, S. (2013), "Mobile learning and professional development: Future building academic work in higher education", In: 30th ascilite Conference. Sydney: Macquarie University, pp.558-596.

16. Nichols, M., Cator, K., \& Torres, M. (2016), Challenge Based Learner User Guide. Redwood City, CA: Digital Promise.

17. Park, Y. (2011), "A pedagogical framework for mobile learning: Categorizing educational applications of mobile technologies into four types", The International Review Of Research In Open And Distributed Learning, Vol. 12, No. 2, pp. 78-102. https://doi.org/10.19173/irrodl.v12i2.791

18. Parsons, D., Ryu, H., \& Cranshaw, M. (2007), “A Design Requirements Framework for Mobile Learning Environments", Journal Of Computers, Vol. 2, No. 4, pp. 1-8.

19. Sharples, M., Corlett, D., \& Westmancott, O. (2002), "The Design and Implementation of a Mobile Learning Resource", Personal And Ubiquitous Computing, Vol. 6, No. 3, pp. 220-234. https://doi.org/10.1007/s007790200021

20. Sharples, M., Taylor, J., \& Vavoula, G. (2005), "Towards a Theory of Mobile Learning", In: van der Merwe, H. \& Brown, T. (Eds.), Mobile Technology: The Future of Learning in Your Hands, 4th World Conference on mLearning (p. 58). Cape Town: mLearn.

21. Sinclair, C. (2008), "Initial and changing student teacher motivation and commitment to teaching", Asia-Pacific Journal of Teacher Education, Vol. 36, No. 2, pp. 79-104. https://doi.org/10.1080/13598660801971658

22. Singh (2016), Virtual Learning Environment segments, lecture note in a course for PhD students, UAE: Hamdan Bin Mohammed Smart University.

23. Tabari, R. (2014), Education Reform in the UAE: An Investigation of Teachers' Views of Change and Factors Impeding Reforms in Ras Al Khaimah Schools. Ras Al Khaimah: Sheikh Saud Bin Saqr Al Qasimi Foundation for Policy Research.

International Journal of Management and Applied Research, 2017, Vol. 4, No. 3 
24. Winkler, T., Günther, S. \& Herczeg, M. (2009), "Moles: Mobile Learning Exploration System", In I. Gibson, R. Weber, K. McFerrin, R. Carlsen \& D. Willis (Eds.), Proceedings of Society for Information Technology \& Teacher Education International Conference 2009 (pp. 3230-3234). Chesapeake, VA: Association for the Advancement of Computing in Education (AACE).

25. UNESCO, (2012). Mobile Learning for Teachers in Africa and the Middle East. UNESCO Working Paper Series on Mobile Learning. Paris, France: United Nations Educational, Scientific and Cultural Organization.

International Journal of Management and Applied Research, 2017, Vol. 4, No. 3 
A Smart Mobile Learning Conceptual Framework for Professional Development of UAE In-Service Teachers

Appendices

Appendix 1: Micro mobile learning course for Office Mix
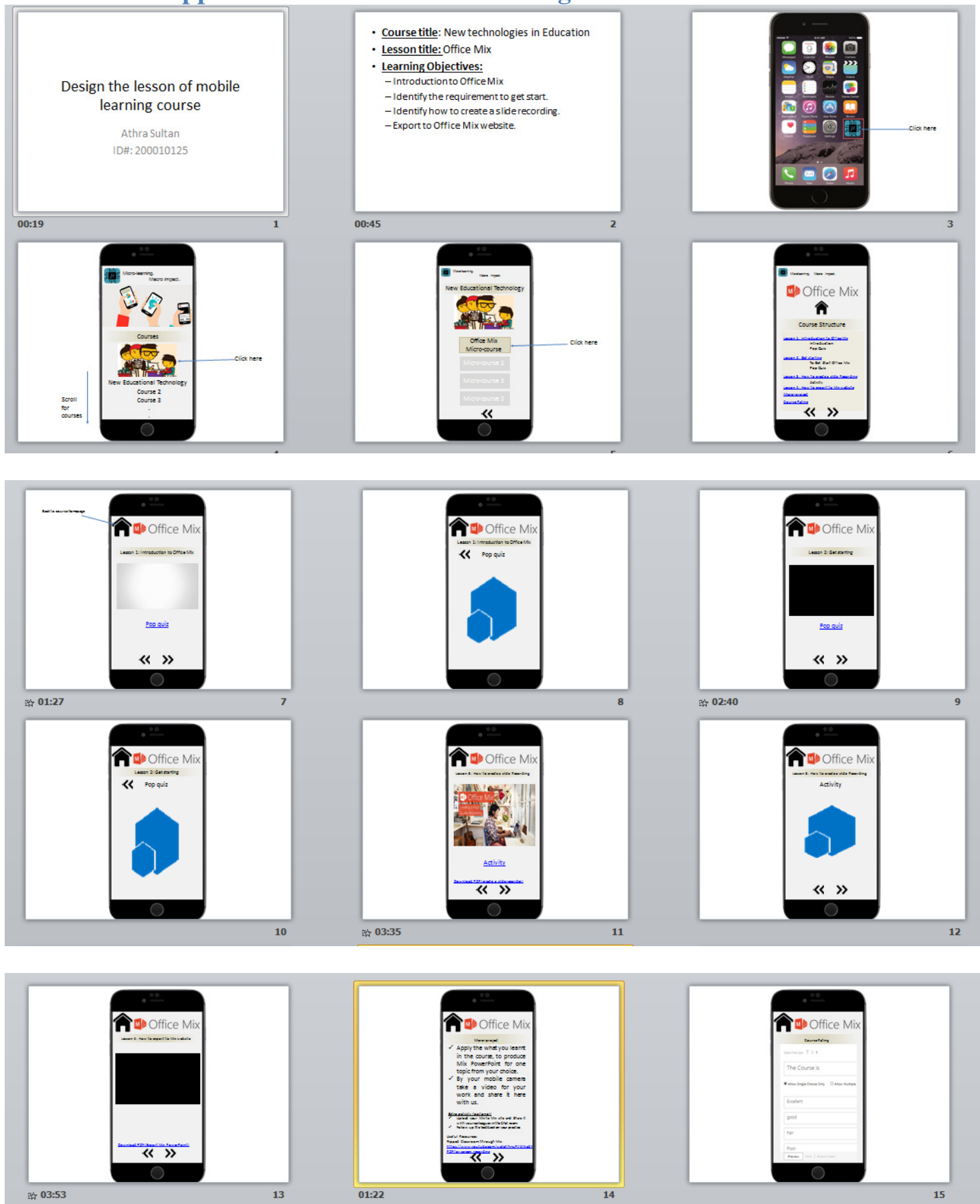

Online in the URL: https://mix.office.com/watch/1143rev2muwx5

International Journal of Management and Applied Research, 2017, Vol. 4, No. 3 
Appendix 2: Teachers' Checklist evaluation for pilot project

Evaluation checklist for mobile learning design

\begin{tabular}{l} 
Criteria \\
\hline Instructional design \\
1) Introduction of the course was simple and \\
direct \\
2) Clear learning outcomes that matched the \\
content \\
3) Content design
\end{tabular}
Poor Good Excellent Comments

- Logical sequence

- Concentrate information

- Relevance

- Content navigation

- Flexible choice of content

4) Proper use of media

5) Activity promotes creativity

6) Promotes discussion

7) Assignment promotes innovative thinking

8) Feedback system provided constructive feedback

Other Features (other sciences and informed practices)

1. Interface

Size, Simple design

2. Usability

Navigation, Organization

International Journal of Management and Applied Research, 2017, Vol. 4, No. 3 